\title{
Does Eustachian tube function affect the outcome of tympanoplasty?
}

\author{
Adel El-Antably ${ }^{1 *} \mathbb{D}$, Khaled Ateya ${ }^{1}$, Mo'men A. Hamela', Sameh Ibrahim² and Mona Hamdy ${ }^{3}$
}

\begin{abstract}
Background: Eustachian tube function has been regarded as a significant factor in the successful outcome of tympanoplasty. Eustachian tube dysfunction has been attributed to many diseases of middle ear cleft ranging from otitis media with effusion to unsafe chronic otitis media. The aim of this study is to evaluate the effect of Eustachian tube function on outcome of tympanoplasty in safe chronic suppurative otitis media patients and detect the correlation between the type of the used graft and the outcome of tympanoplasty. This study included 60 randomly selected patients diagnosed with safe chronic suppurative otitis media. Eustachian tube function was tested with tympanometry and Toynbee's test. All patients underwent tympanoplasty type I.

Results: Successful statistically significant outcome was observed in $83.3 \%$ of patients with normal eustachian tube function, while in $60 \%$ of patients with eustachian tube dysfunction $(p<0.05)$.

Conclusion: Eustachian tube function significantly affects the outcome of tympanoplasty surgery. No significant correlation was noted between the type of the used graft and the outcome of tympanoplasty.

Keywords: Otitis media, Eustachian tube, Tympanoplasty
\end{abstract}

\section{Background}

Eustachian tube (ET) normal function is crucial in maintaining the middle ear aeration and middle ear pressure. ET dysfunction may lead to middle ear diseases as well as affects the postoperative outcome in patients with chronic suppurative otitis media. Preoperative assessment of the ET function is important to anticipate the postoperative outcome. Normal ET function is essential for restoration of the integrity middle ear and normal hearing [1].

Tympanoplasty is a procedure to eradicate the middle ear disease and to reconstruct the hearing mechanism. The aims of tympanoplasty are to provide a dry ear and to restore hearing as much as possible. Many factors have been attributed for the success, out of which ET function is considered one of the most important [2].

\footnotetext{
*Correspondence: adel_antably@hotmail.com

${ }^{1}$ Department of Otorhinolaryngology, Faculty of Medicine, Cairo University, Cairo, Egypt

Full list of author information is available at the end of the article
}

The reported success rates of tympanoplasty surgeries were higher in patients with normal ET function. On the other hand, success rates were lower in patients with ET dysfunction. Therefore, preoperative assessment of the ET function can improve the outcome by choosing the proper surgical technique for each case [3].

The aim of the current study is to evaluate the effect of Eustachian tube function on outcome of tympanoplasty in safe chronic suppurative otitis media patients and detect the correlation between the type of the used graft and the outcome of tympanoplasty.

\section{Methods}

This interventional study was carried on 60 patients having the diagnosis of tubotympanic type of chronic suppurative otitis media (CSOM). Patients were randomly selected from outpatient clinic of Otorhinolaryngology department at Faculty of Medicine, Cairo University, Egypt.
Springer Open (c) The Author(s). 2021 Open Access This article is licensed under a Creative Commons Attribution 4.0 International License, which permits use, sharing, adaptation, distribution and reproduction in any medium or format, as long as you give appropriate credit to the original author(s) and the source, provide a link to the Creative Commons licence, and indicate if changes were made. The images or other third party material in this article are included in the article's Creative Commons licence, unless indicated otherwise in a credit line to the material. If material is not included in the article's Creative Commons licence and your intended use is not permitted by statutory regulation or exceeds the permitted use, you will need to obtain permission directly from the copyright holder. To view a copy of this licence, visit http://creativecommons.org/licenses/by/4.0/. 
Inclusion criteria included CSOM (tubotympanic type) of more than 3 months duration. Exclusion criteria included patients younger than 14 years or older than 50 years, history of previous ear operation, atticoantral CSOM, acute infection, general diseases as diabetes mellitus and nasal or nasopharyngeal manifestations (as allergic rhinitis, chronic sinusitis and adenoids). The study was approved by the Ethical and Research Committee. Written informed consents were obtained from all participants or their parent or legal guardian in the case of children under 16 years. Full otorhinolaryngological examination was performed including full history taking.

Audiological evaluation was done using Clinical audiometer Madsen Itera II (Natus, Denmark) calibrated according to the international standard organization (ISO) standard, in a sound treated room (Amplisilence model E), and a TDH 39 earphones. Tonal audiometry was done in the frequency range $0.25-8 \mathrm{kHz}$. Speech audiometry: speech reception threshold (SRT) using Arabic spondee words [4] and word discrimination score (WDS) using Arabic phonetically balanced (PB) words [5]. Immittancemetry was done using Madsen Zodiac 901 (Natus, Denmark), calibrated according to the ISO standard. Tympanometry and Eustachian tube function (The Toynbee's test) were done. The impedance audiometer (Toynbee's test) assesses the ET function in perforated tympanic membrane. It is programmed to increase and decrease the middle ear air pressure. Then, the patient is asked to swallow repeatedly. The change in in the middle ear pressure is recorded with each swallow. The pressure change is represented graphically as a step ladder graph if the ET function is normal. If pressure persists after five swallows, then ET dysfunction is diagnosed (Fig. 1).
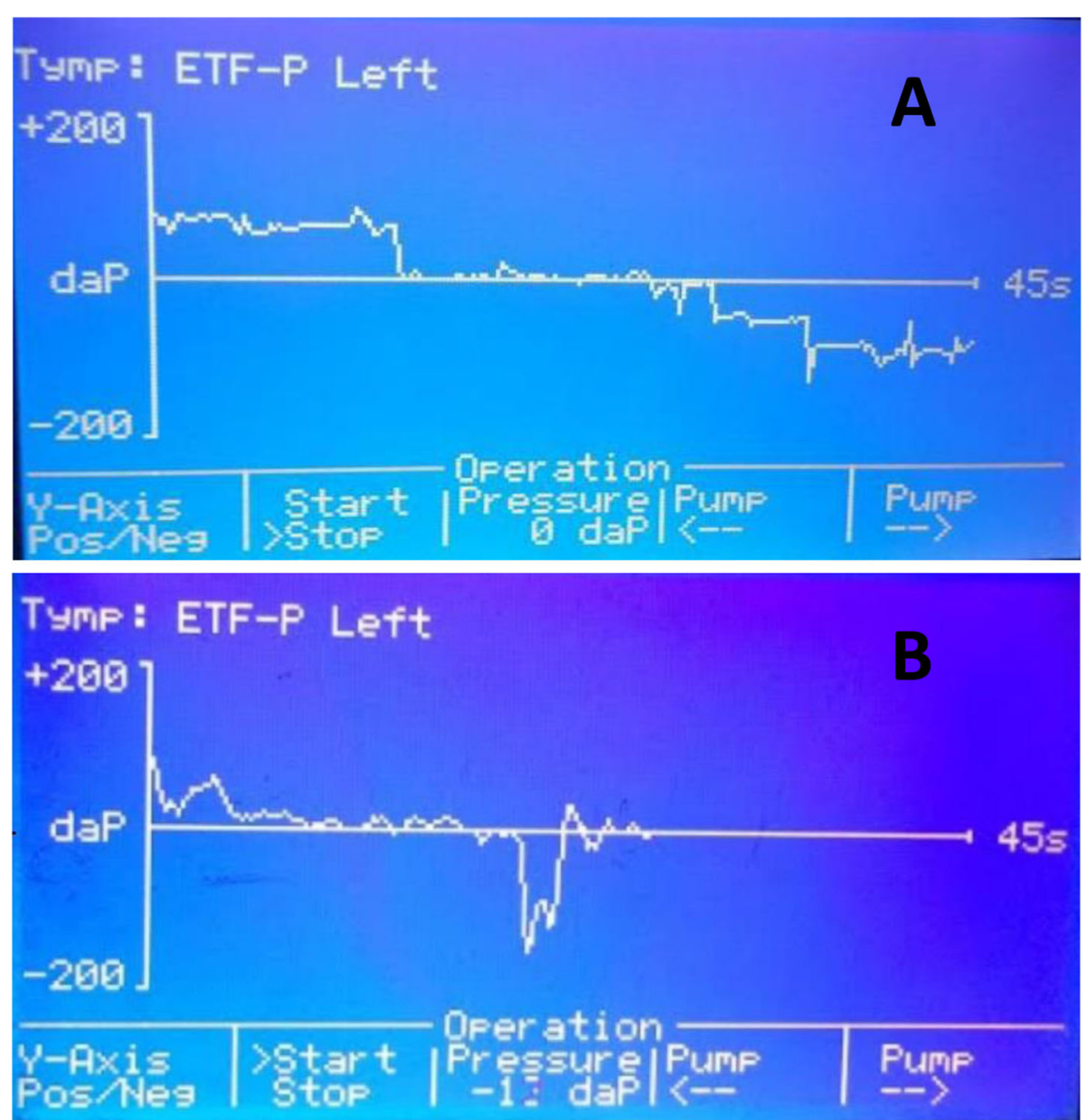

Fig. 1 Impedance audiometer showing step ladder graph in a case of ET function (A) and near flat curve with persistent pressure in a case of ET dysfunction (B) 
Table 1 Relation between ET function and the tympanoplasty outcome

\begin{tabular}{|c|c|c|c|c|c|c|}
\hline & & \multicolumn{4}{|c|}{ ET Function } & \multirow{3}{*}{$p$ value } \\
\hline & & \multicolumn{2}{|c|}{ Normal } & \multicolumn{2}{|c|}{ Dysfunction } & \\
\hline & & Count & $\%$ & Count & $\%$ & \\
\hline \multirow[t]{2}{*}{ Tympanoplasty } & Healed & 25 & $83.3 \%$ & 18 & $60.0 \%$ & 0.045 \\
\hline & Failed & 5 & $16.7 \%$ & 12 & $40.0 \%$ & \\
\hline
\end{tabular}

All patients underwent underlay tympanoplasty type I under general anesthesia with temporalis fascia or cartilage (tragal or conchal) grafting through post auricular approach and underlay technique. Follow up visits were scheduled at the $1^{\text {st }}$ and $2^{\text {nd }}$ weeks postoperatively then at the $6^{\text {th }}$ postoperative month. The outcome was considered successful if the graft was completely healed at the $6^{\text {th }}$ postoperative month.

Sample size calculation was done using the primary outcome (the success of the middle ear reconstructive surgeries). The calculated minimum proper sample size was 27 participants in each arm to be able to reject the null hypothesis with $80 \%$ power at $\alpha=0.05$ level using one way analysis of variance and test ratio between the two groups at 1:1 and with an accommodated $20 \%$ dropout rate. Sample size calculation was done using MedCalc software version 19.1 (MedCalc Software Ltd, Belgium).

Data were coded and entered using the statistical package for the Social Sciences (SPSS) version 26 (IBM Corp., USA). Data was summarized using mean, standard deviation, median, minimum and maximum in quantitative data and using frequency (count) and relative frequency (percentage) for categorical data. For comparing categorical data, Chi square $\left(x^{2}\right)$ test was performed. Exact test was used instead when the expected frequency is less than 5
[6]. $p$ values less than 0.05 were considered as statistically significant.

\section{Results}

This prospective study was done on 60 patients diagnosed as tubotympanic CSOM. Age ranged between 15 to 40 years old. Males to females were 20:40.

Patients were divided into two groups according to ET function. First group included 30 patients with normal ET function (50 \%) and the second group included 30 patients with ET dysfunction (50\%). Both groups were then subdivided into 2 equal subgroups, 15 patients each, according to the used graft whether temporalis fascia or tragal / conchal cartilage. All patients underwent tympanoplasty type I.

The outcome was recorded at the $6^{\text {th }}$ postoperative month. Out of 30 ears with normal ET function, graft was healed in 25 ears $(83.3 \%)$ and failed with residual perforation in $5(16.7 \%)$ ears. Moreover, out of 30 ears with ET dysfunction, graft was healed in $18(60 \%)$ ears and failed in $12(40 \%)$ ears. Results were statistically significant $(p$ value $=0.045)$ (Table 1).

In the normal ET function group, successful outcome was reported in 12 patients $(80 \%)$ of temporalis fascia graft (Fig. 2) subgroup and 13 patients $(86.7 \%)$ of cartilage graft (Fig. 3) subgroup $(p$ value $=1)($ Table 2$)$.

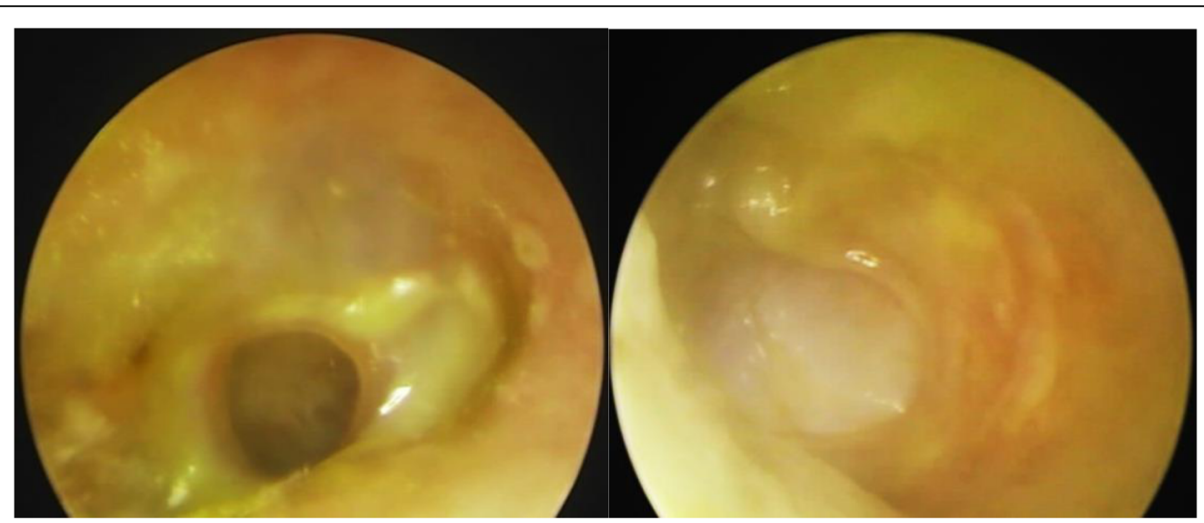

Fig. 2 Preoperative and postoperative endoscopic examination of a successful case of fascia tympanoplasty 


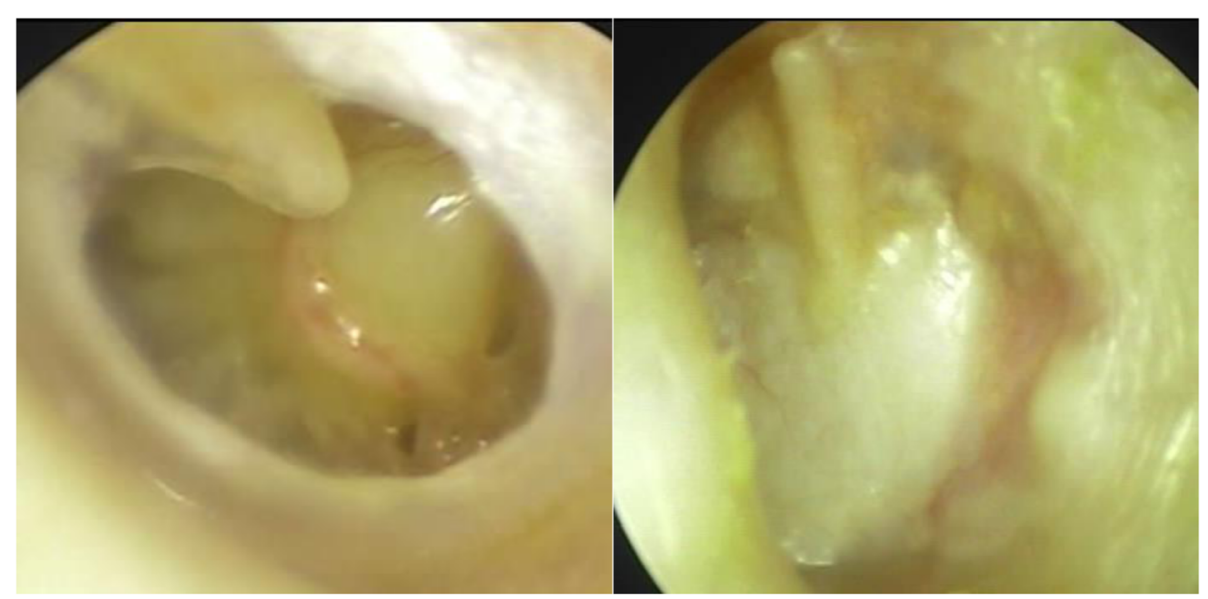

Fig. 3 Preoperative and postoperative endoscopic examination of a successful case of cartilage tympanoplasty

In the ET dysfunction group, successful outcome was reported in 10 patients $(66.7 \%)$ of temporalis fascia graft subgroup and 8 patients $(53.3 \%)$ of cartilage graft subgroup $(p$ value $=0.456)($ Table 3$)$.

\section{Discussion}

In the current study, statistically significant correlation was detected between ET function and result of the tympanoplasty type I surgery ( $p$ value $<0.05$ ). Graft uptake rates were better in the normal ET function group compared with ET dysfunction group, with success rates of $83.3 \%$ and $60 \%$ in both groups respectively (Table 1 ). Prasad et al. in 2014 [7] reported similar results, as graft uptake in normal ET function patients was $80 \%$ versus $50 \%$ in those with ET dysfunction. Sen et al. (1998) [8] described graft uptake rates of $80 \%$ and $66 \%$ in normal ET function and in ET dysfunction respectively. Cohn et al. in 1979 [9] stated that those with normal ET function showed successful outcome in $95 \%$ and $69 \%$ in those with ET dysfunction. Tos in 1998 [10] and Priya et al. in 2012 [11] testified that the ET function is an important influence in

Table 2 Comparison between the tympanoplasty results using temporalis fascia graft and cartilage graft in the normal ET function group

\begin{tabular}{|c|c|c|c|c|c|c|}
\hline & & \multicolumn{4}{|c|}{ Normal ET function group } & \multirow{3}{*}{$p$ value } \\
\hline & & \multicolumn{2}{|c|}{ Temporalis fascia } & \multicolumn{2}{|c|}{ Cartilage } & \\
\hline & & Count & $\%$ & Count & $\%$ & \\
\hline \multirow[t]{2}{*}{ Tympanoplasty } & Healed & 12 & $80.0 \%$ & 13 & $86.7 \%$ & 1 \\
\hline & Failed & 3 & $20.0 \%$ & 2 & $13.3 \%$ & \\
\hline
\end{tabular}

the successful outcome of tympanoplasty due to its role in ventilation of the middle ear.

\section{Type of graft and its effect on healing}

In this study, no significant correlation was noted between the type of the graft and the outcome of tympanoplasty with $p$ value $>0.05$ in both groups. These results agree with the study of Lyons et al. in 2016 [12] who observed that there was no evidence of superiority of cartilage graft over temporalis fascia graft in tympanoplasty type I. On the contrary, Jalali et al. in 2017 [13] reported that cartilage graft seemed to show a higher graft healing rate compared with temporalis fascia graft. Moreover, Mohamad et al. in 2012 [14] described that tympanoplasty using cartilage graft with or without perichondrium had better morphological outcome than temporalis fascia graft.

\section{Conclusion}

ET function has a significant impact on tympanoplasty outcome. Pre-operative ET function evaluation should be done routinely prior to middle ear surgery. Moreover, no correlation has been found between the type of used graft and the outcome of tympanoplasty.

Table 3 Comparison between the tympanoplasty results using temporalis fascia graft and cartilage graft in the ET dysfunction group

\begin{tabular}{|c|c|c|c|c|c|c|}
\hline & & \multicolumn{4}{|c|}{ ET dysfunction group } & \multirow{3}{*}{$P$ value } \\
\hline & & \multicolumn{2}{|c|}{ Temporalis fascia } & \multicolumn{2}{|c|}{ Cartilage } & \\
\hline & & Count & $\%$ & Count & $\%$ & \\
\hline \multirow[t]{2}{*}{ Tympanoplasty } & Healed & 10 & $66.7 \%$ & 8 & $53.3 \%$ & 0.456 \\
\hline & Failed & 5 & $33.3 \%$ & 7 & $46.7 \%$ & \\
\hline
\end{tabular}




\section{Abbreviations}

CSOM: Chronic suppurative otitis media; ET: Eustachian tube;

ISO: International standard organization; PB: Phonetically balanced;

SRT: Speech reception threshold; WDS: Word discrimination score

\section{Acknowledgements}

Not Applicable.

\section{Authors' contributions}

$\mathrm{AE}, \mathrm{KA}, \mathrm{MH}, \mathrm{SI}$ and $\mathrm{MH}$ shared in the study design, data collection, analysis and interpretation of data. Audiological evaluation was done by $\mathrm{MH}$. All authors read and approved the final manuscript.

\section{Funding}

This research did not receive any specific grant from funding agencies in the public, commercial, or not-for-profit sectors.

\section{Availability of data and materials}

The datasets used and/or analyzed during the current study are available from the corresponding author on reasonable request.

\section{Declarations}

\section{Ethics approval and consent to participate}

All procedures performed in this study were in accordance with the ethical standards of the institutional and/or national research committee and with the 1964 Helsinki declaration and its later amendments or comparable ethical standards.

All measures for data collection were treated with confidentiality. This study was conducted in Cairo University Hospital after receiving the approval from the Research Ethics Committee. Reference number is not applicable. Informed written consents to participate in the study were provided by all individual participants (or their parent or legal guardian in the case of children under 16 years) after explanation of the study objectives before enrolment in the study.

\section{Consent for publication}

Not applicable.

\section{Competing interests}

All authors declare that they have no competing interests.

\section{Author details}

'Department of Otorhinolaryngology, Faculty of Medicine, Cairo University, Cairo, Egypt. ${ }^{2}$ Department of Otorhinolaryngology, Hearing and Speech Institute, Cairo, Egypt. ${ }^{3}$ Department of Audiology, Faculty of Medicine, Cairo University, Cairo, Egypt.

Received: 5 April 2021 Accepted: 20 June 2021

Published online: 08 July 2021

\section{References}

1. Kumar N, Madkikar NN, Kishve S, Chilke D, Shinde KJ (2012) Using middle ear risk index and ET function as parameters for predicting the outcome of tympanoplasty. Indian J Otolaryngol Head Neck Surg 64(1):13-16. https:// doi.org/10.1007/s12070-010-0115-4

2. Choi SH, Han JH, Chung JW (2009) Pre-operative evaluation of Eustachian tube function using a modified pressure equilibration test is predictive of good postoperative hearing and middle ear aeration in type 1 tympanoplasty patients. Clin Exp Otorhinolaryngol 2(2):61-65. https://doi. org/10.3342/ceo.2009.2.2.61

3. Callioglu EE, Tijen Ceylan B, Kuran G, Demirci S, Tulaci KG, Caylan R (2013) Cartilage graft or fascia in tympanoplasty in patients with low middle ear risk index (anatomical and audological results). Eur Arch Oto-RhinoLaryngology 270(11):2833-2837. https://doi.org/10.1007/s00405-012-2238-6

4. Soliman S, Fathalla A, Shehata M (1985) Development of Arabic staggered spondee words (SSW) test. In: Proceedings of the 8th Ain Shams medical congress. 2nd ed, Egypt, pp 1220-1246

5. Soliman S (1976) Speech discrimination audiometry using Arabic phonetically-balanced words. Ain Shams Med J 27:27-30
6. Chan YH (2003) Biostatistics 103: qualitative data - tests of independence. Singap Med J 44(10):498-503

7. Prasad V, Prasad KC, Shenoy V, Raghavendra Rao A, Panduranga Kamath M, Sowmya V (2014) A study of middle ear reconstruction, the degree of functional restoration and causes of graft failure following chronic ear disease. Egypt J Ear, Nose, Throat Allied Sci 15(2):103-108. https://doi.org/1 0.1016/j.ejenta.2014.04.001

8. Sen S, Guha S, Biswas A, Ghosh L (1998) A comparative study of methods of evaluation of Eustachian tube functions in chronic otitis media. Indian J Otol 4:147-149

9. Cohn AM, Schwaber MK, Anthony LS, Jerger JF (1979) Eustachian Tube Function and Tympanoplasty. Ann Otol Rhinol Laryngol 88(3):339-347. https://doi.org/10.1177/000348947908800308

10. Tos M (1998) Importance of Eustachian Tube Function in Middle Ear Surgery. Ear, Nose Throat J 77(9):744-747. https://doi.org/10.1177/01455613 9807700911

11. Priya K, Karthikeyan P, Coumare VN, Sambandan AP (2012) Evaluation of Eustachian tube function in chronic suppurative otitis media (tubotympanic type) with reference to its treatment outcome. Indian J Otol 18(4):179-183. https://doi.org/10.4103/0971-7749.104794

12. Lyons SA, Su T, Vissers LET, Peters JPM, Smit AL, Grolman W (2016) Fascia compared to one-piece composite cartilage-perichondrium grafting for tympanoplasty. Laryngoscope. 126(7):1662-1670. https://doi.org/10.1002/la ry. 25772

13. Jalali MM, Motasaddi M, Kouhi A, Dabiri S, Soleimani R (2017) Comparison of cartilage with temporalis fascia tympanoplasty: A meta-analysis of comparative studies. Laryngoscope. 127(9):2139-2148. https://doi.org/10.1 002/lary.26451

14. Mohamad SH, Khan I, Hussain SSM (2012) Is Cartilage Tympanoplasty More Effective Than Fascia Tympanoplasty? A Systematic Review. Otol Neurotol 33(5):699-705. https://doi.org/10.1097/MAO.0b013e318254fbc2

\section{Publisher's Note}

Springer Nature remains neutral with regard to jurisdictional claims in published maps and institutional affiliations.

\section{Submit your manuscript to a SpringerOpen ${ }^{\circ}$ journal and benefit from:}

- Convenient online submission

- Rigorous peer review

- Open access: articles freely available online

High visibility within the field

- Retaining the copyright to your article

Submit your next manuscript at $>$ springeropen.com 